\title{
Design and Evaluation of the Electronic Class Record for the Makiling National High School
}

\author{
Rhowel M. Dellosa \\ Lyceum of the Philippines-Laguna
}

\begin{abstract}
This study aimed to design, develop, deploy and evaluate an electronic class record. Electronic worksheet software is used to develop the electronic class record and several arithmetic operators and functions like VLOOKUP, IF, AVERAGE, COUNTIF. A worksheet template was developed to accept name of teacher, course title, section, schedule, room, student number, student name, grade level, gender, date of each classes, base grade, test items attendance and performance of the students. The electronic class record automatically computes the grades of the students following the prescribed grading system of Makiling National High School. Developmental process and prototyping method were utilized to develop the electronic class record. Testing, deployment and evaluation have been initiated to observe its acceptability. The electronic class record will be used effective School Year 2014-2015.
\end{abstract}

Keywords: Electronic Class Record, Makiling National High School

\section{INTRODUCTION}

Before the school year of the next academic calendar starts, teachers are preparing for their stuffs. One of their stuff is the class record. The class record is a document contains the record of performance of their students. In several institutions class record is distributed. The teachers will use it by transferring the grades of students from source in any form to the class record. Human error is always present in computation of grades. The time it takes to transfer the record from the source to the template is also of great concerns and time consuming.

To help the teachers in their class records concerns, an electronic class record was designed and developed. The intention of this is to come up with a design of electronic class records that will be utilized by the teachers of Makiling National High School.

\section{Literature Review}

According to Dellosa (2013), the deployed electronic class record was very useful to teachers and resulted to an overall evaluation of an average mean of 3.46 and average standard deviation of 0.538 with an overall interpretation of agree result. User-friendliness ranked as first with the highest mean value of 3.8. The output's security and flexibility were rated with strongly agree. In terms of accuracy, reliability, validity, and efficiency, the output was rated with agree which also implies that the evaluators were satisfied on the developed system. It is found out that the deployed electronic class record is acceptable in terms of accuracy, efficiency, reliability, security, user-friendliness, flexibility and validity.

The study entitled "e-DoX: DEPED Student Grade Records Management System with Implementation of Advanced Encryption Standard and PKI Infrastructure for the Department of Education in the Province of Cavite (2013)" which aims to develop an online based application to aid private and public schools in submission of reports on promotions in the province of Cavite was used to guide the researcher on how to treat and interpret data and results.

An electronic class record for the LPU-Laguna and LPU-St. Cabrini is developed as a substitute to the conventional ways of recording the performance of the students. The researcher based his method of developing the electronic class record to lessen the activities and customized the content of the output (Dellosa, 2013).

DEPED Order No 73, Series of 2012 entitled "Guidelines and Assessment and Learning Outcomes under the K12 Basic Education Curriculum" was used to guide the researcher as the basis of computation of grades. The level of assessment that includes knowledge, process or skills, understanding and product and level of proficiency are some of the useful information that serves as inputs in the completion of the study.

The International Organization for Standardization (ISO) was founded in 1946 in order to unify industrial standards by providing a single set of standards that would be recognized and followed (Praxiom Research Group). The ISO 9126 was developed in 1991 to provide a framework for evaluating software quality. It was refined over a ten year period (Abran, 2003). The metrics introduced and validated from this study were considered and became the basis of the researcher to come up with the survey evaluation form of the electronic class records. 
Sommerville (2011) discussed that security is one of the important attributes of the system to protect itself from accidental or incidental attacks. He also tackled some of the methodology on how to develop the system including Rapid Application Development, prototyping and formal methods. The researcher focused on the use of prototype method information and applied it in this study.

Chen's (1997) study entitled "Computer-based Document Management System", leads to an efficient way to automatically import, index, categorize, store, search, retrieve, manipulate and archive electronic documents. This will be entrant information for online application. The researcher used the discussion and output of this study to come up with a study recommendation that online grade viewer is possible.

According to Chua, B.B. \& Dyson, L.E. (2004), there is a widespread use of e-learning systems and investment in them but there is no consensus on a standard framework for evaluating the quality of the output. In their study, they used ISO 9126 Quality Model as a useful tool for evaluating systems, particularly for teachers and educational administrators. They also demonstrated the validity of the model and used to detect design loopholes. The ISO 9126 is used by the researcher as a guide to come up with a survey and evaluation instrument.

\section{CONCEPTUAL FRAMEWORK}

The input includes the basic knowledge of Microsoft Excel application software, which is capable of arithmetic computations. The process includes brainstorming with the possible users, development, training and evaluation. Several arithmetic operands and functions include VLOOKUP, IF, COUNTIF and other arithmetic functions are also utilized. The ISO 9126 software evaluation is used to evaluate the electronic class record. An input-processoutput presentation of conceptual framework is also provided.

INPUT

Knowledge about
Microsoft Excel
Knowledge about
computation of
grades
Knowledge on
DEPED order No.
73, S 2012
Knowledge with the
current system used
by the teachers of
Makiling National
High School
Knowledge with the
existing electronic
class record

\section{PROCESS}

\section{OUTPUT}

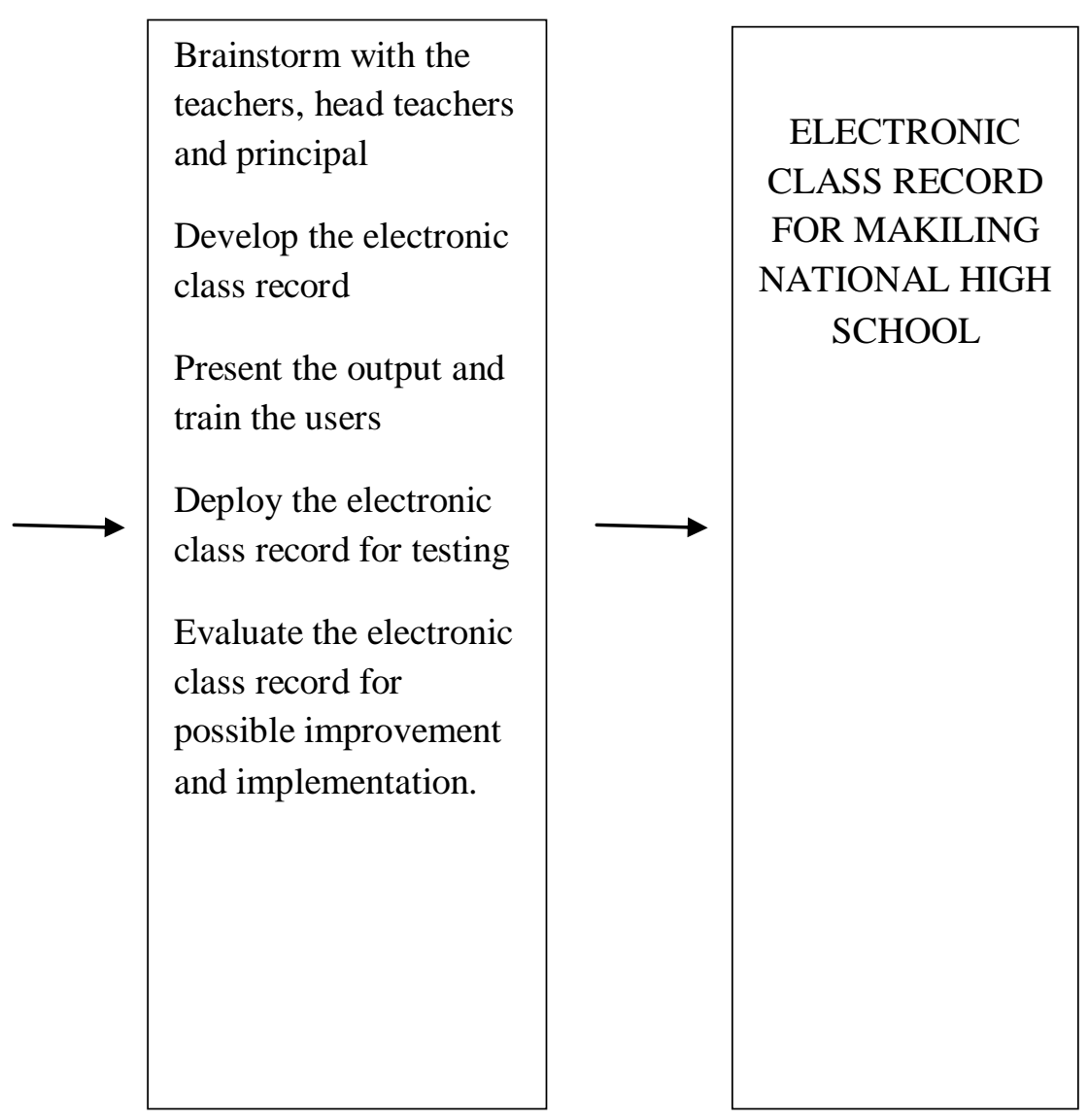

Figure 1. Developmental Framework 
Objectives of the Study

The general objective of this study is to develop an electronic class record for Makiling National High School.

Specifically, the study aimed to:

1. develop an electronic class record following the prescribed grading system of Makiling National High School

2. test the functionality of the electronic class record

3. determine the acceptability of the electronic class record for possible implementation.

\section{Significance of the Study}

This study has great significance to end users of the institution and the Makiling National High School.The end users will benefit for the reason that the study will make their life easier for grade computation. The Makiling National High School will benefit because this would contribute to uplift the application of technology.

\section{Scope and Delimitation}

The study was conducted in Makiling National High School from December 3, 2013 to February 28, 2014. Microsoft Excel is used to develop the electronic class record. Inputs from the end users, the principal and teachers, were carefully analysed. During deployment, revisions were made for further improvement and acceptance. Training sessions with the teachers and principal on how to use the electronic class record were also conducted. Other unexpected events such as power outage and the Microsoft Excel issues and updates from Microsoft are no longer part of the study.

\section{MATERIALS AND METHODS}

\section{Research Design}

In this study, the researcher used developmental method that includes designing, developing, testing and evaluating the study. Series of tests were conducted to determine acceptability in terms of accuracy and reliability of computation of grades.

\section{Locale of the study}

The researcher conducted focus group discussions to determine the requirements and prescribed grading system of the school. Evaluation from the end-users of Makiling National High School was conducted to determine the accuracy, efficiency, reliability, security, user-friendliness, flexibility, validity of the system. The usefulness of the electronic class record was also determined by evaluation.

\section{Respondents of the study}

The researcher conducted a focus group discussions and evaluation from the principal, head teacher and teachers of Makiling National High School. The development stage was conducted from January 2014 February 2014 wherein principal, head teacher and some of the teachers were asked about the current system used in computation of grades, prescribed class record and the current system.

\section{Research instrument and technique used}

The researcher used survey and evaluation instrument. The objective of the focus group discussions is to determine the requirements in which survey is integrated. The researcher adopted an evaluation instrument from the ISO 9126 standard and also from the study of Rommel B. Dya, Mary Jane A. Laridab and Dr. Bartolome T. Tanguilig entitled "e-DoX:DEPED Student Grade Records Management System with Implementation of Advanced Encryption Standard and PKI Infrastructure". The evaluation instrument are composed of respondent's profile, software characteristics in terms of accuracy, efficiency, reliability, flexibility, security, user-friendliness and validity and respondent's suggestions and recommendations for the improvement of the developed electronic class record.

\section{Statistical Treatment of Data}

The researcher used descriptive statistics to determine the acceptability and respondent's suggestions and recommendations for the improvement of the developed electronic class record.

\section{Research Process}

Prototype model was used in developing the electronic class record. The following are the research process of the research. 


\section{1) Planning and analysis}

In this phase, information are gathered to be able to determine the need of the study. This will also guide the researcher on what procedures and actions to be used in the study. The type of user, capability of the output, implementers and the environment where output will be used must be obtained during this phase. It will also determine the currently used system by the users and will introduce new idea on how to apply the output of the study that has advantages over the existing system. Functionality of the system will be also defined in this stage.

\section{2) Testing}

This phase will determine the output's performance in terms of accuracy and acceptability. It will guide the researcher to ISO 9126 software evaluation.

\section{3) Deployment}

The use of this phase is to determine if the system is easy to use. It is also expected feedback form the users will be collected and further improvement will be applied for possible implementation.

\section{4) Evaluation}

This phase will let the prospect users answer the survey and evaluation form in the form of focus group discussion to determine the acceptability of the system.

Below is the step-by-step procedure during the conduct of the study.

1. Plan and analyse the current system and establish objectives and solution to current need.

2. Gather necessary data from the principal, head teacher and teachers.

3. Design the electronic class record with the use of Microsoft Excel.

4. Present the electronic class record to teachers for further improvement

5. Integrate in the revision the comments from the teachers and prospect users.

6. Deploy the output to the teachers.

7. Conduct training sessions to end-users.

8. Get feedback from the teachers and revise as necessary.

9. Evaluate the electronic class record.

10. Finalize the study document.

11. Submit the end product to the Makiling National High School and the research document to the research department.

\section{RESULTS AND DISCUSSION}

A. The Electronic Class record of the Makiling National High School

1) Worksheet Attendance Tab

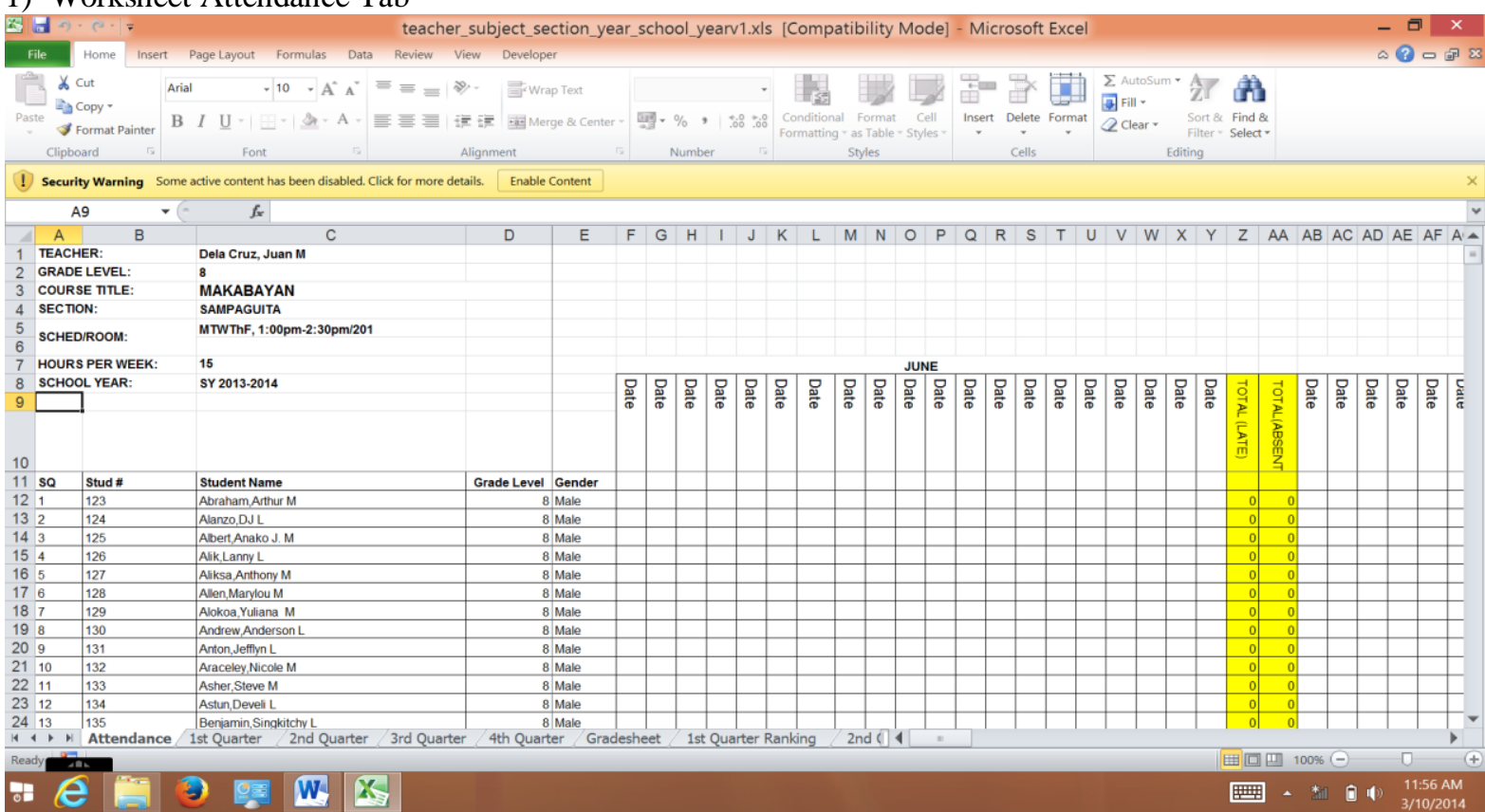

Figure 2. Worksheet Attendance Tab Output of Electronic Class Record 
Figure 2 above shows the workheet attendance tab of electronic class record. The user inputs for every attendance column are the date and letter ' $\mathrm{L}$ ' for late student and ' $\mathrm{A}$ ' for absence student.

2) $1^{\text {st }}$ Quarter Worksheet Tab

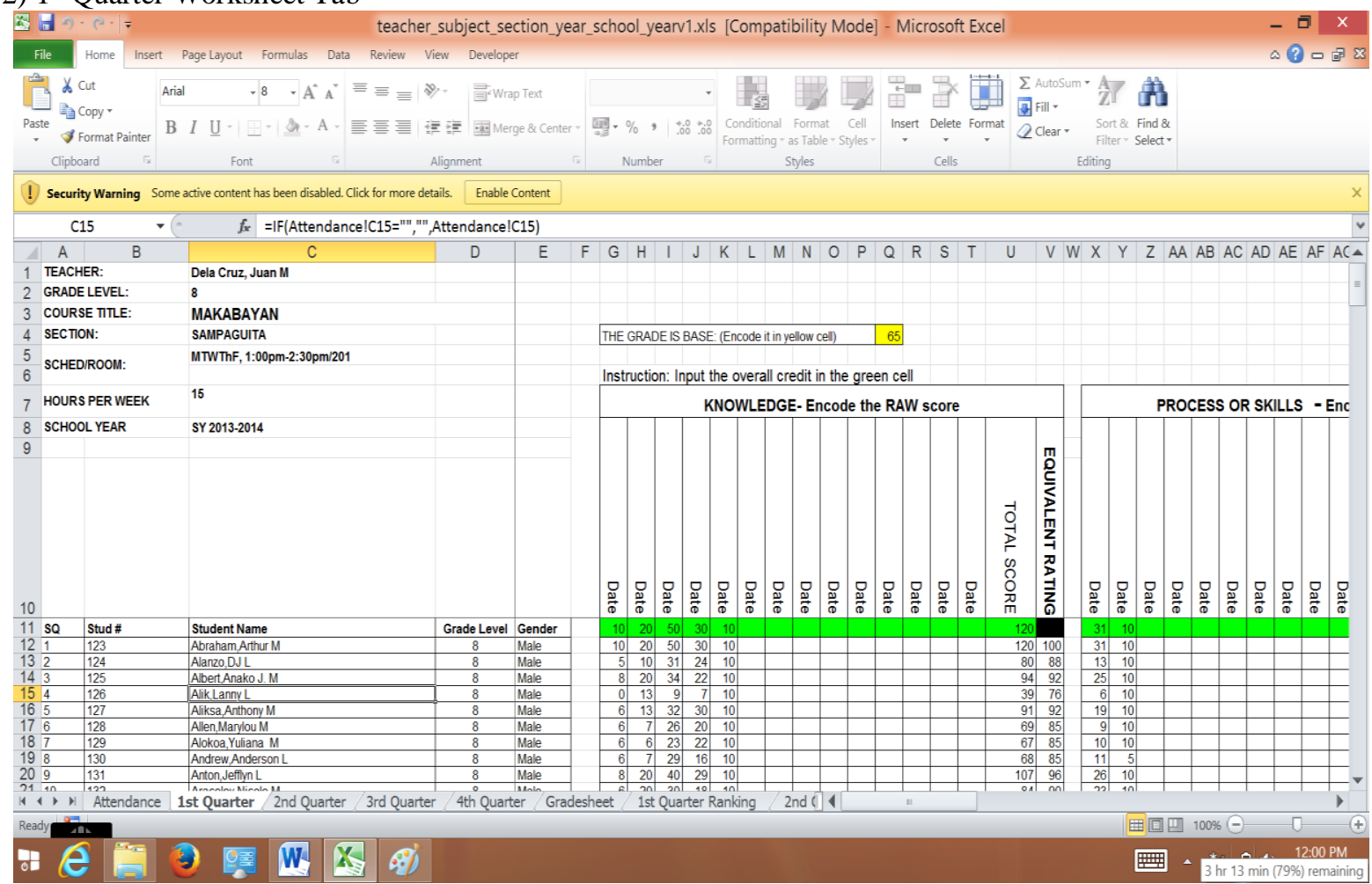

Figure 3. Worksheet $1^{\text {st }}$ Quarter Tab Output of Electronic Class Record

3) $2^{\text {nd }}$ Quarter Worksheet Tab

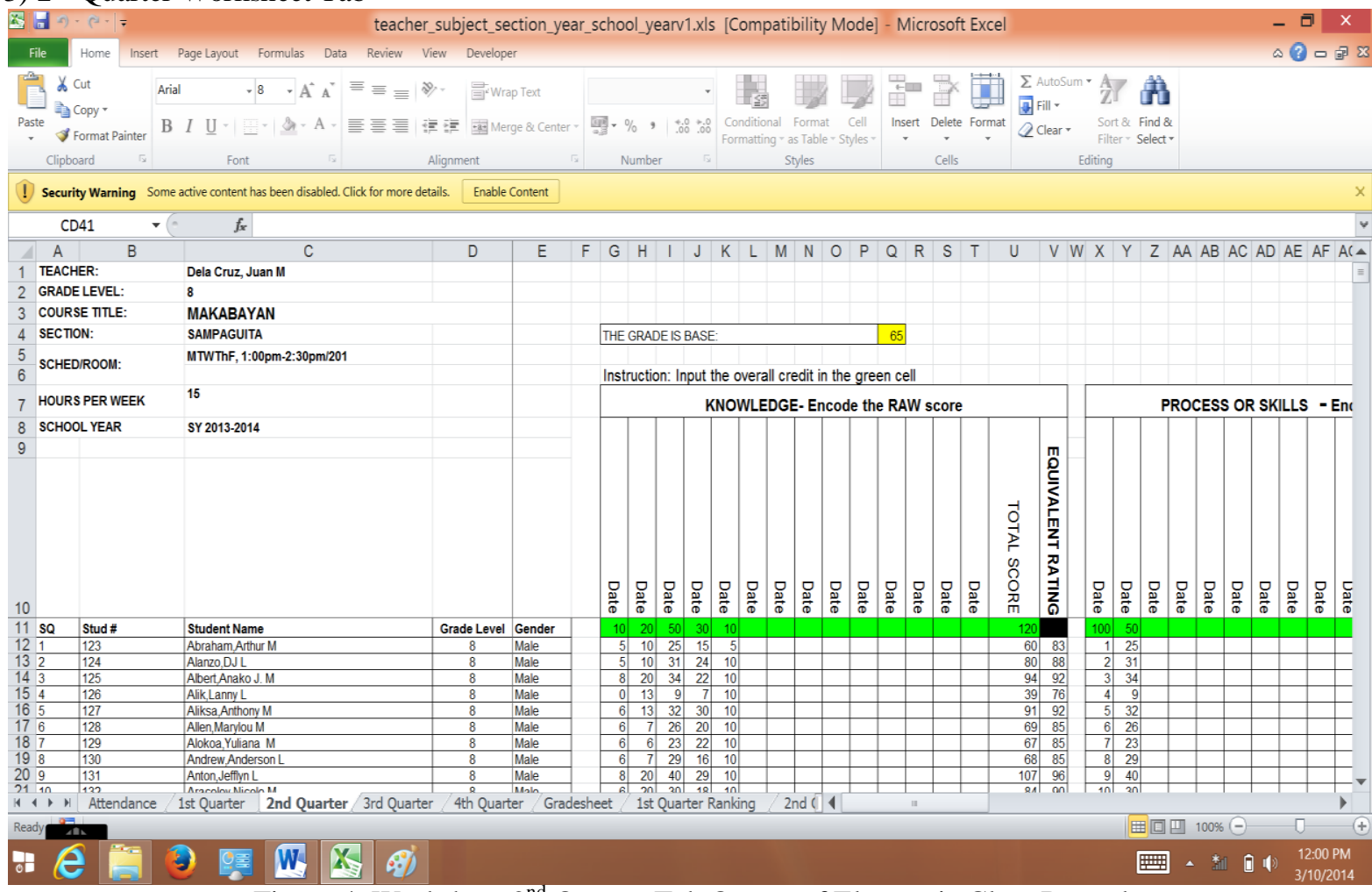

Figure 4. Worksheet $2^{\text {nd }}$ Quarter Tab Output of Electronic Class Record 
4) $3^{\text {rd }}$ Quarter Worksheet Tab

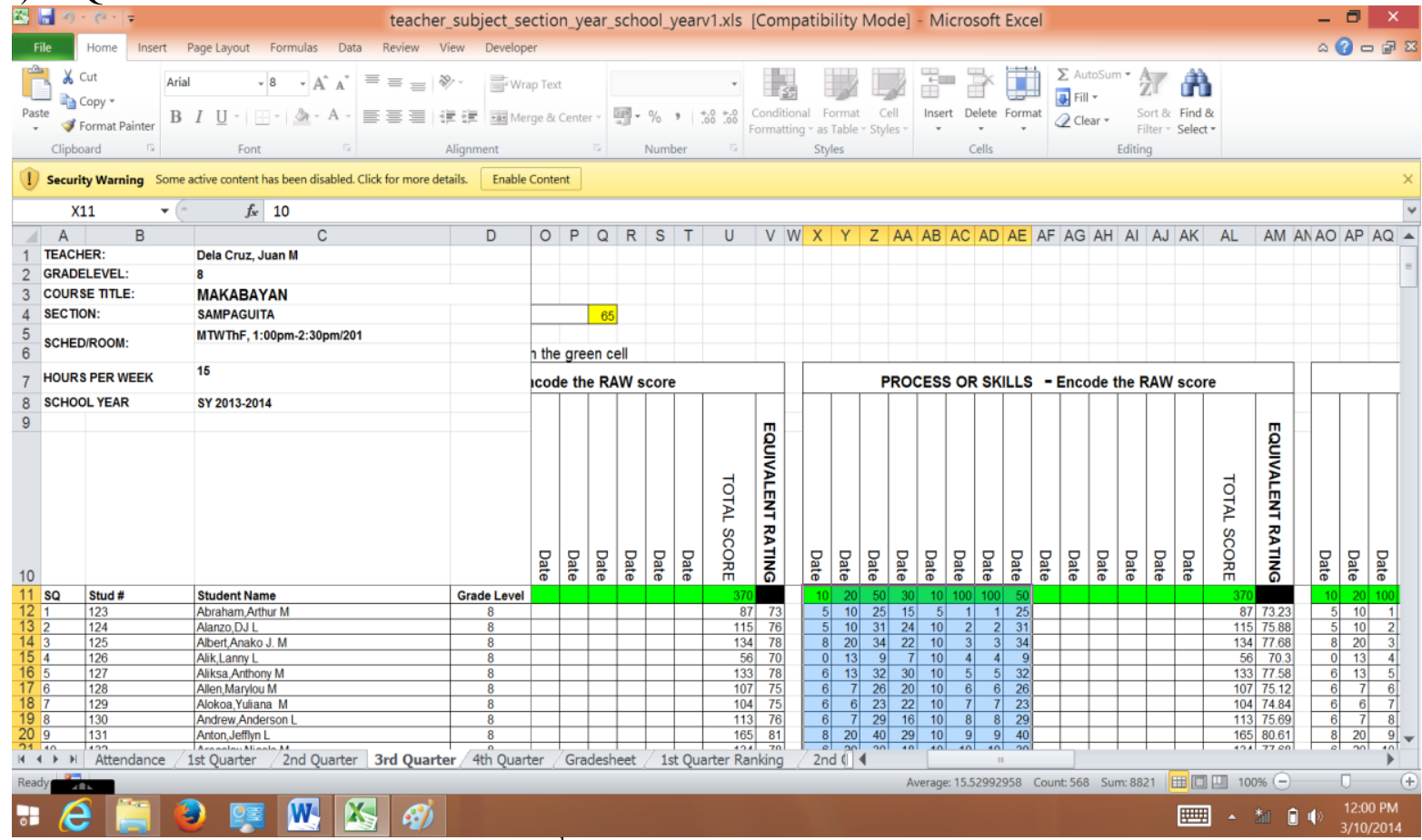

Figure 5. Worksheet $3^{\text {rd }}$ Quarter Tab Output of Electronic Class Record

5) $4^{\text {th }}$ Quarter Worksheet Tab

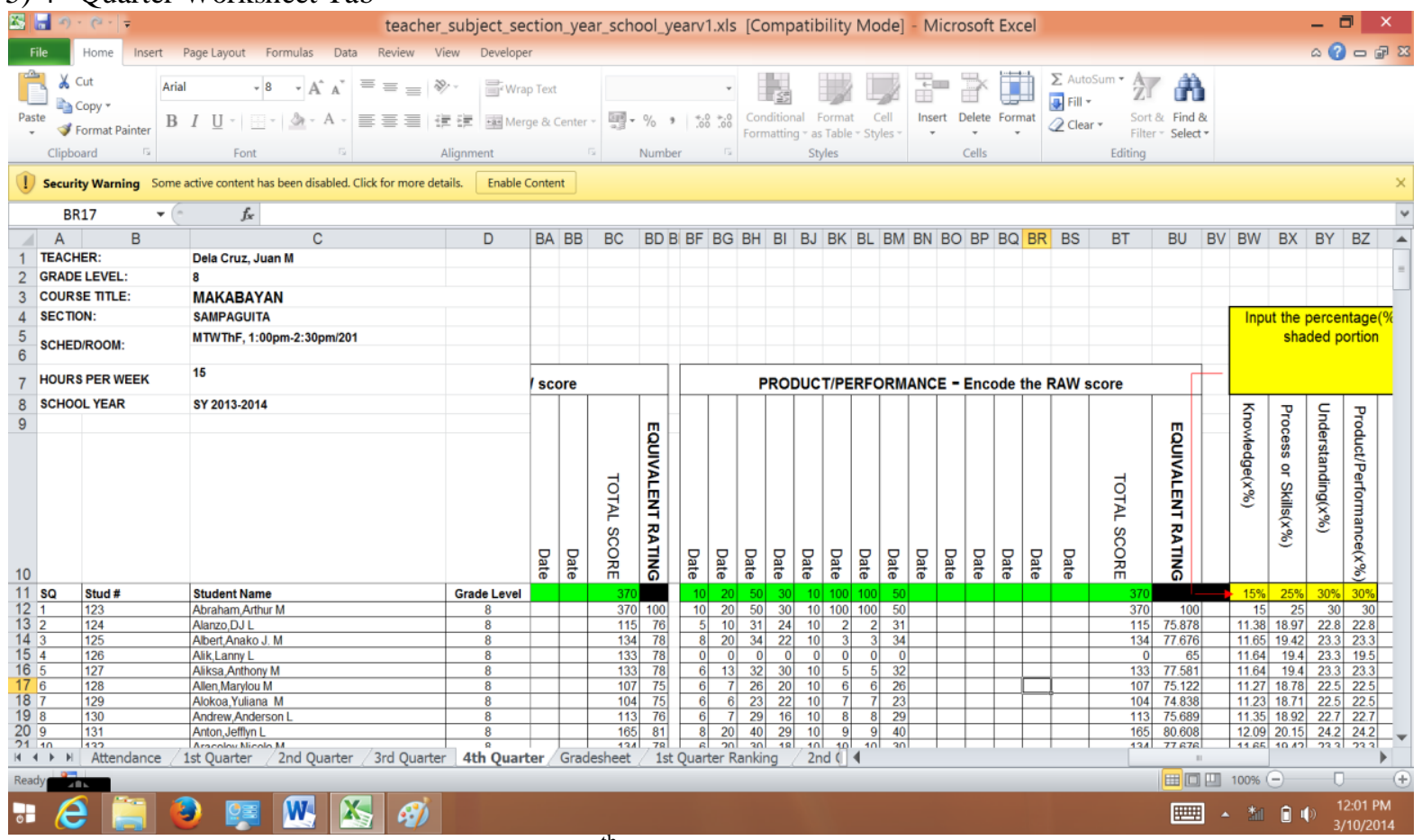

Figure 6. Worksheet $4^{\text {th }}$ Quarter Tab Output of Electronic Class Record

Figures $2,3,4,5$, and 6 are the $1^{\text {st }}, 2^{\text {nd }}, 3^{\text {rd }}$, and $4^{\text {th }}$ quarter tab that perform the computation of grades of students. Initial setup of electronic class record should be done prior to its use. User inputs such as grade base and percentage per level of assessment must be encoded to the designated cell locations. Grade base remain to be variable for future use. User inputs such as date, total score per activity and the raw score of student for each level of assessment must be also first encoded by the user.

5) Grade Sheet Worksheet Tab 


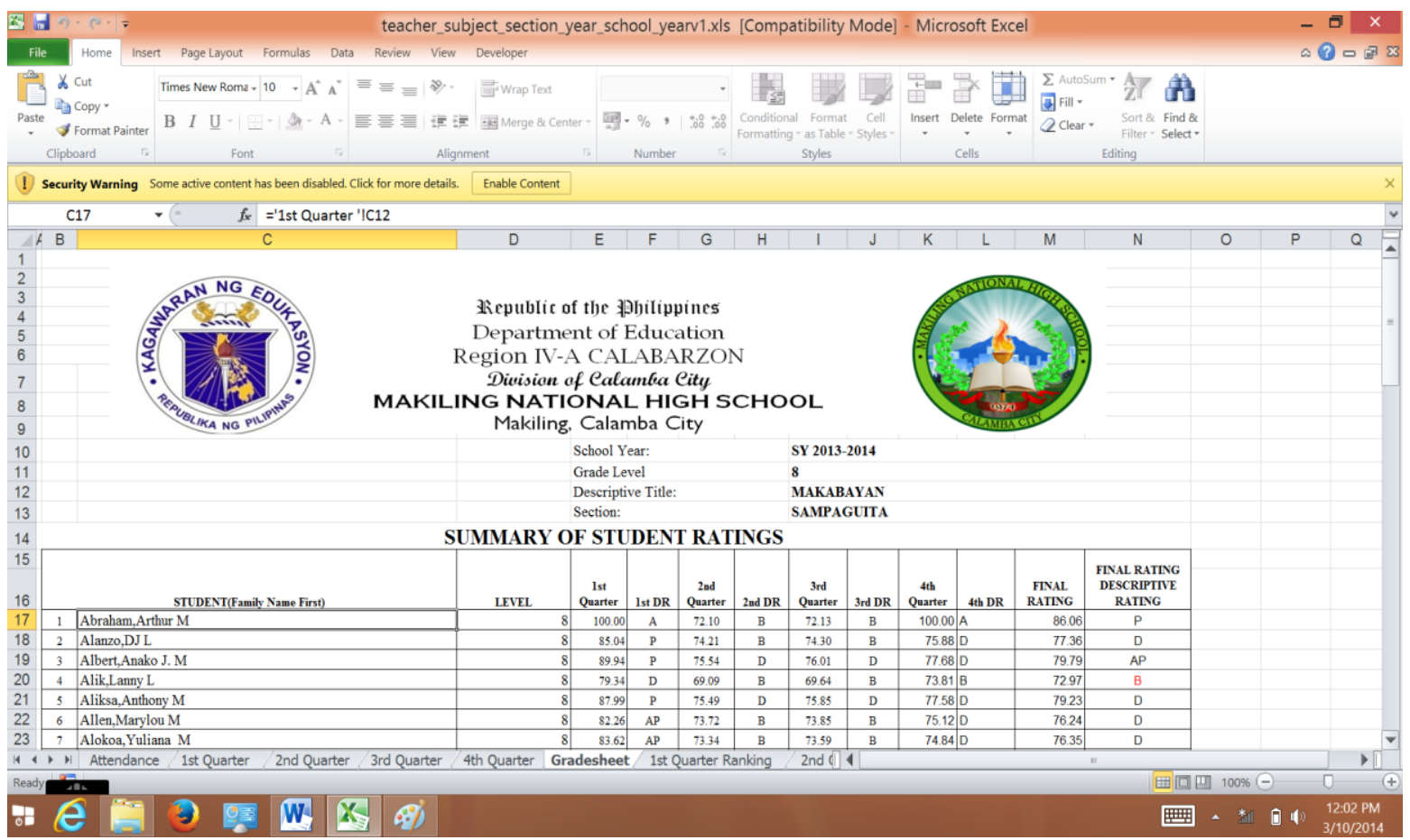

Figure 7. Worksheet Gradesheet Tab Output of Electronic Class Record

Figure 7 shows the grade sheet of class record. It is the summary of all computed grades per quarter. The formula below is just an example of transferring the content from one worksheet tab to another.

6) Rank of students

The teacher would need to know the rank of the student each quarter. The figure below is the worksheet tab for the ranking of students for quarter.

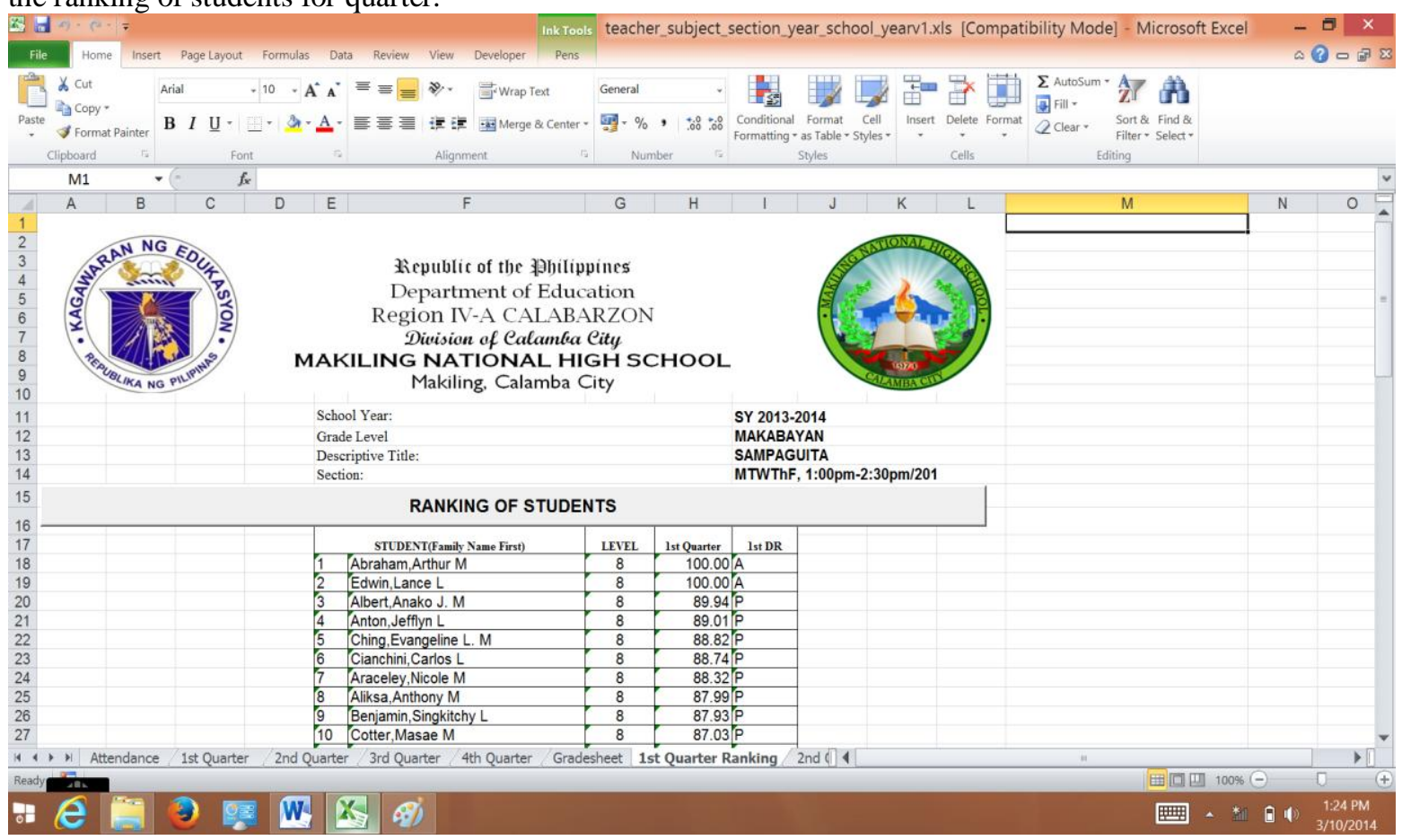

Figure 8. Rank of Student Tab

\section{B. Result of test of functionality}

A series of tests were conducted to determine the functionality of the electronic class record in terms of accuracy and reliability. These series of tests were conducted from January 2014 to February 2014. Feedbacks from the end users were collected to ensure that the output provides accurate and reliable result. This will also 
serves as the guide for the revisions of electronic class record. Feedbacks from the end users are accuracy of grade computation, worksheet tab dedicated only for the attendance of the students, variability of grade base and the output's capability to compute the grade based on the encoded grade base and revision of worksheet labeling to become more user-friendly.

\section{Result of acceptability evaluation}

Teachers and head teacher of Makiling National High school attested that the developed electronic class record will be used this SY 2014-2015. With regard to acceptability, all of them believed that the electronic class record will make their record keeping easier compared with the existing method. The electronic class record will be implemented effective June 2014.

\section{Summary of Findings}

\section{CONCLUSION AND RECOMMENDATION}

Microsoft Excel application software was useful in developing the electronic class record. Electronic class record functionality is determined with the input data like name of teacher, course code, course title, section, schedule, room, student number, student name, grade level, gender, date of each classes, base grade, test items, attendance and performance of the students.

Developmental process and prototyping method were utilized to develop the electronic class record. Testing, deployment and evaluation have been initiated to observe its acceptability.

The attendance sheet tab is used to tabulate the absences and tardiness of each student. Character " $\mathrm{A}$ " is designated code for absence, and " $\mathrm{L}$ " for tardiness. The total number of absences and tardiness can be automatically computed. It is displayed in the designated cells every month. The total accumulated absences and tardiness is also computed and is displayed in the designated cell.

First (1st) to fourth (4th) quarter worksheet tabs are of the same functions. Its function is to accept inputs from the end user. The inputs from the user are the total number of credit points and the actual score of students for each assessment activity, date per assessment activity and the percentage equivalent per total assessment. These worksheet tabs will automatically compute and provide grades and their equivalent level of proficiency in the designated cells.

The grade sheet tab is used to display the summary of grades of each student per quarter and the final grade of each student. It also shows the summary of total students who belong with the different levels of proficiency. This grade sheet tab is one of the documents to be submitted to the principal per grading period.

Summary of ranking per quarters and finals is also provided to easily determine the top and least performing students.

A series of tests and investigation were conducted to ensure the acceptability of the output from the user. Focus group discussions were used to determine the acceptability of the electronic class records.

\section{CONCLUSION}

Based on the findings of the study, the researcher concluded that the electronic class record is developed for the teachers of the Makiling National High School. It follows the grading system as per Department of Education standards. With the aid of computer system, class record can be easily. Finally, the electronic class record is acceptable and subject for implementation effective SY 2014-2015.

\section{Recommendations}

Several recommendations are made by the end users and administrators like the security of previous encoded grade must not be changed anymore once it is submitted. The output of the electronic class record may be the basis for report card. Moreover, the output of the electronic class record may be considered as an input to an online grade viewer.

\section{REFERENCES}

[1] Chua, B.B. \& Dyson, L.E. (2004). Applying the ISO 9126 Model to the Evaluation of an E-learning System. In R. Atkinson, C. McBeath, D. Jonas-Dwyer \& R. Phillips (Eds), Beyond the Comfort zone: Proceedings of the 21st ASCILITE Conference (pp. 184-190). Perth, 5-8 December. http://www.ascilite.org.au/conferences/perth04/procs/chua.html

[2] Sommerville (2011). Software Engineering IE, 9th ed., Addison-Wesley

[3] Dellosa R.M. (2012). Design and Evaluation of Electronic Class Record for the LPU-Laguna and LPUSt. Cabrini.

[4] Dellosa R.M. (2013). Design and Evaluation of Electronic Class Record for the LPU-Laguna International School. 
[5] DEPED Order No 73, Series of 2012 Entitled " Guidelines and Assessment and Learning Outcomes Under the K-12 Basic Education Curriculum

[6] Dya, R.B., Laridab, M.A. \& Tanguilig, B.T (2013). e-DoX:DEPED Student Grade Records Management System with Implementation of Advanced Encryption Standard and PKI Infrastructure

[7] Software Evaluation Criteria (n.d.). Retrieved February 2012, from associationdatabase.com/aws/NCDA/asset_manager/get_file/3404

[8] Chen (n.d.). Computer-based Document Management System. Los Gatos, California: Caere Corporation. 